possibility of the future, then perhaps Prof. Perry's gloomy picture of the decay of Great Britain may be falsified. The place of our coal-mines in our national assets would then be taken by the vast areas of sunlit land in our Colonial Empire, for fuel-production would then become a question of the number of acre-hours of sunlight available.

I should like to add that what I have said in this letter does not at all lessen the urgency of Prof. Perry's plea for efficient engines; in fact, I think that what I have pointed out tends to strengthen the demand for a great national effort at the sclution of these pressing problems. At present we are, in matters of energy, "robbing posterity" while it is eminently desirable that we should discover a way-if there be one-of "paying our way," and I think that in fuel farming such a way may perhaps be found.

443 Gillott Road, Edgbaston, April 27.

WALTER RosenHain.

Mr. Rosenhain is mistaken as to the ignorance of inventors; many engines have been invented and referred to in newspapers during the last thirty years for utilising solar heat. I may remark that such heat engines may be very efficient, because the available temperature may be very high indeed. I have sometimes wondered why metallurgists neglected the possibility of obtaining very high temperature furnaces from the heat of the sun. As to the energy available, at p. I4 of my book on "Steam" I say :"On one square foot of Egypt the heat energy received in one year from the sun is about $10^{9}$ foot pounds, or 500 horse-power hours." This is nearly equivalent to the energy of a coating of coal all over Egypt one foot thick, and promises a future for the Sahara and other cloudless regions of the earth. I therefore admit that I did not give sufficient weight to this consideration of the direct heat from the sun, and I am very glad that Mr. Rosenhain has drawn attention to my neglect.

J. Perry.

\section{Experimental Mathematics.}

Prof. Perry's syllabus in practical mathematics has now been published two or three years, and the results of actual experience of its working may have some interest. We have in this institute about three hundred students of mathematics, in. cluding boys in the day school as well as older evening students, who follow a course on the lines of Prof. Perry's syllabus, and in both classes the adoption of the method has aroused an increased interest in the subject. This increase of interest seems to be due to the fact that the method is essentially experimental as well as deductive. Mathematics is treated as a science rather than, according to a common tradition, as an "arts" subject. The student is taught to investigate the facts for himself by experiment in the form of actual plotting and measurement and numerical calculation, just as in the study of such a science as electricity he investigates a law for himself in the laboratory and, usually at a later stage, proves in his theoretical work that that law follows from his previous knowledge. This is not merely a question of illustrating elementary geometry, but the practice may be carried with advantage into what are usually considered quite advanced parts of his work. However well a student may know the analytical proofs involved, he greatly improves the firmness of his grasp by actually plotting, with various numerical values of the constants, curves to represent such a case, for instance, as the small oscillations of a stiff spring, or the form of a bent beam. In pure mathematics, especially in differential geometry, many examples may be found, and, in fact, the method of conformal representation, which has been so fruitful in the theory of functions and its applications, is really an instance of this method. Besides increasing the average student's interest in his work, these "direct vision" methods, used systematically throughout a student's course, give more solidity and a clearer definition to his ideas than it seems possible to attain by abstract reasoning alone.

My special object, however, in writing is to insist on the value of the method as a lngical training. We sometimes hear of the "invaluable logical training " of Euclid with the implied assumption that other methods of treating mathematics are illogical. This view seems to ignore the lact that there is an inductive as well as a deductive logic. If a boy is taught from the beginning to verify all theorems by actual plotting and measurement, he trains, not only his logical powers of deductive reasoning in proving his theorem from its premises, but also his equally logical powers of inductive reasoning from observation NO. I 697 , VOL. 66] and experiment. From the point of view of educational theory this seems a sounder method than to restrict his training to one form of logical reasoning to the neglect of the other. The deductive logic of the syllogism was the only form known in the time of Euclid, but it is scarcely necessary to say that inductive logic now holds a recognised place, and the whole development of modern experimental science has proceeded by its methods.

John Stuart Mill, as is well known, devotes a very scanty consideration to syllogistic reasoning on the ground that "Formal Logic therefore, which ... have represented as the whole of logic properly so called, is really a very subordinate part of it, not being directly concerned with the process of Reasoning or Inference in the sense in which that process is a part of the Investigation of Truth," and that "The foundation of all sciences, even demonstrative or deductive sciences, is induction."

This may, perhaps, be the explanation of the difficulty which so many boys as well as older students feel in comprehending demonstrative geometry. Most teachers of evening students have met with men of considerable ability and some maturity of mind who have little or no difficulty with algebraical work, but can never comprehend the meaning of a proposition in Euclid. The syllogistic method of reasoning seems to find no avenue into their minds, although they can reason well enough from observed facts. Such people are usually set aside as having no mathematical gift, but all must have notions of space and time, and consequently of change and a rate of change, and if rigid deductive methods were so essential as is often supposed to the science which puts those notions into scientific form, they would scarcely be incomprehensible to so many. If anyone has the power of comprehending the facts of a science such as chemistry, he must have some power of putting that knowledge into scientific form, and so anyone whose experience is given in space and time can scarcely be quite without the power of un. derstanding the science which deals with those conditions of his experience. In fact, if students who seem to be without mathematical power are aliowed to approach the subject by an ex. perimental method, they find no difficulty in understanding it and may in time come to grasp the significance of deductive methods. In secondary schools of the classical and mathematical type, boys who are not on the science side are at present almost without the opportunity of developing their inductive logical powers, with the exception of the few who reach the stage where they can draw their own conclusions from the facts of philology or history. Experimental mathematics might in this case be made to supply the place of the missing experi. mental training.

However one may admire the symmetry of an ideal rigid body of mathematical knowledge, built up in the mind of the learner so that each step is made to depend by flawless abstract reasoning on what has gone before, and so on down to necessary axioms at the foundations, such a process cannot be carried out in the practice of education. It is sometimes said that a student should not be allowed to use any process or to believe any theorem until he can render a complete and perfect reason for it. But if a student is to follow such a method he should not be allowed to use $0 \cdot \dot{3}$, until he can justify his use of it from a knowledge of the meaning of a limiting value and of the criteria for the convergency of series, nor may he use $\sqrt{2}$ as a number until he has mastered the modern theory of irrational numbers and made up his mind whether to hold opinion with Dedekind and Weierstrass, that the conception of an irrational number is to be based on a purely arithmetical theory, or with. Du Bois-Reymond, that it is essentially geometrical and insepar. ably connected with linear magnitude. It is obvious that no teacher can attempt such a course; these difficulties are always passed over without proof.

In the method of practical mathematics, this practice is frankly recognised as legitimate and natural, and is systematically extended to other parts of mathematics.

Whatever may be true of the superstructure, the fundamental notions of pure mathematics have not been built up by strict deductive process, but by a series of successive approximations to the truth. The conception of a limiting value is a case in point. Until the time of Cauchy, the existence of a limiting value was thought to be self-evident on geometrical grounds in such a case as that of the area of a polygon inscribed in a circle. Cauchy in his treatment of definite integrals recognised that it was necessary to prove that a definite limiting value existed in such a case, but it was only in 1883 , that a completely neces- 